\title{
The World Health Organization "Rehabilitation 2030: a call for action"
}

\author{
Francesca GIMIGLIANO ${ }^{1 *}$, Stefano NEGRINI 2,3
}

\begin{abstract}
${ }^{1}$ Department of Mental and Physical Health and Preventive Medicine, University of Campania "Luigi Vanvitelli", Naples, Italy; ${ }^{2}$ Section of Physical and Rehabilitation Medicine, Department of Clinical and Experimental Sciences, University of Brescia, Brescia, Italy; ${ }^{3}$ Don Gnocchi Foundation and Institute for Research and Care, Milan, Italy
\end{abstract}

*Corresponding author: Francesca Gimigliano, Department of Mental and Physical Health and Preventive Medicine, University of Campania "Luigi Vanvitelli”, Via de Crecchio 4, 80138, Naples, Italy. E-mail: francescagimigliano@gmail.com

\section{A B S T R A C T}

February $6^{\text {th }}-7^{\text {th }}, 2017$ might become a memorable date in the future of rehabilitation. On these two days, the World Health Organization (WHO) has summoned over 200 stakeholders in the Executive Board Room of the WHO Headquarters in Geneva, Switzerland. Their common aim was to a launch the "Rehabilitation 2030" call to action and to present the WHO Recommendations on rehabilitation in health systems. These initiatives are meant to draw attention to the increasing unmet need for rehabilitation in the world; to highlight the role of rehabilitation in achieving the Sustainable Development Goals proposed by the United Nations; to call for coordinated and concerted global action towards strengthening rehabilitation in health systems. The aim of this paper is to report on the scientific events of these 2 days, which will most likely mark the history of rehabilitation.

(Cite this article as: Gimigliano F, Negrini S. The World Health Organization "Rehabilitation 2030: a call for action". Eur J Phys Rehabil Med 2017;53:155-68. DOI: 10.23736/S1973-9087.17.04746-3)

Key words: Health status - World Health Organization - Rehabilitation - Health planning guidelines.

$\mathrm{F}_{\mathrm{s}-\mathrm{s}}$ ebruary $6^{\text {th }}-7$ th, 2017 will be a date to remember in the future of rehabilitation. On these two days, the World Health Organization (WHO) gathered together over 200 stakeholders in the Executive Board Room of WHO Headquarters, Geneva, including government officials, organizations representing rehabilitation service user groups and providers, funding bodies, international professional organizations, research institutions, non-governmental organizations, and WHO and other United Nations agencies. ${ }^{1}$ Figure 1 illustrates the geographical distribution of the participants. ${ }^{2}$ They have been involved in the WHO "Rehabilitation 2030: a call for action" meeting and the presentation of the WHO Recommendations on rehabilitation in health systems.

The aims of this meeting were: ${ }^{1}$

- "to draw attention to the increasing unmet needs for rehabilitation";

- "to highlight the role of rehabilitation in achieving the Sustainable Development Goals (SDGs) proposed by the United Nations"; 3

- "to call for coordinated and concerted global action towards strengthening rehabilitation in health systems". 


\section{COPYRIGHT ${ }^{\odot} 2017$ EDIZIONI MINERVA MEDICA}

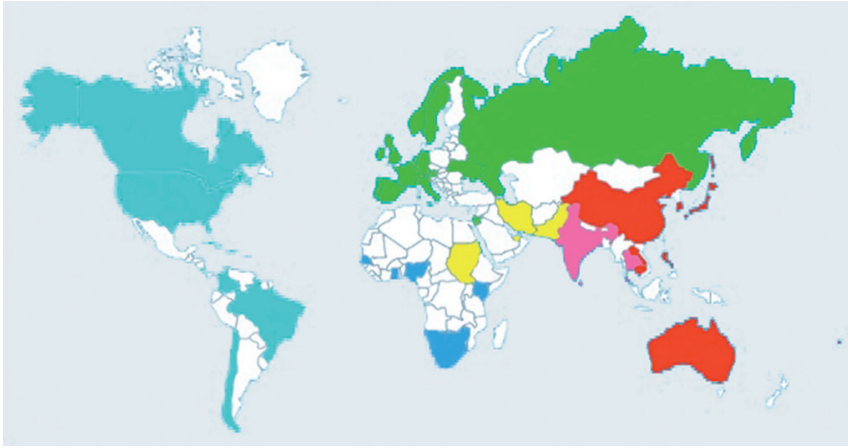

Figure 1.-Geographical representation of the participants to the meeting Rehabilitation 2030: a call for action. ${ }^{2}$

The colors used are to differentiate the six main regions of the World Health Organization (African Region, Region of the Americas, SouthEast Asia Region, European Region, Eastern Mediterranean Region, and Western Pacific Region).

The aim of this paper is to report on this important political and scientific event, which will most likely mark the history of rehabilitation.

\section{The preparatory documents}

Before the meeting some preparatory documents were shared with all the participants. We present here a summary of these background papers that are accessible from $\mathrm{WHO}$ website. ${ }^{4}$

\section{The concept note}

The ageing of the population along with the increasing prevalence of noncommunicable diseases, the improvement of medical care, and the development and availability of assistive products are increasing the demand for rehabilitation services worldwide. ${ }^{5,} 6$ Nevertheless, the capacity to provide rehabilitation is still limited or non-existent in many parts of the world, particularly in low- and middle-income countries (LMIC). 5, 7, 8

The WHO global disability action plan 2014-2021 sets out actions for WHO, Member States and partners, towards the objective of strengthening and extending rehabilitation. ${ }^{7}$ Rehabilitation is the key health strategy for the achievement of Sustainable Development Goal 3 (SDG3) - "Ensure healthy lives and promote wellbeing for all at all ages." ${ }^{3}$ It is primarily aimed at optimizing functioning, and support those with health conditions to be as independent as possible and to actively participate in the society.

The extent and scope of unmet rehabilitation needs requires an urgent joint and coordinated global action by all rehabilitation stakeholders. "Rehabilitation 2030: a call for action" meeting is meant to be an opportunity to discuss with rehabilitation stakeholders concerted actions to scale up rehabilitation as the key health strategy to ensure healthy lives and promote well-being by 2030 .

\section{The need to scale up rehabilitation 9}

The need to scale up rehabilitation is clearly stated in the second objective of the WHO global disability action plan 2014-2021 "Better health for all people", i.e. to "strengthen and extend rehabilitation, habilitation, assistive technology, assistance and support services, and community-based rehabilitation." 7

Recently published data on the Global Burden of Disease Study (GBD) ${ }^{10}$ shows that $74 \%$ of the total number of years lived with disability (YLDs) in the world is due to health conditions that cause limitations in functioning and can benefit from rehabilitation. ${ }^{11-20}$ About $15 \%$ of the total number of YLDs is caused by health condi-

TABLE I.-Global prevalence and YLDs for health conditions associated with severe levels of disability (2005-2015) (modified from World Health Organization). ${ }^{9}$

\begin{tabular}{|c|c|c|c|c|c|c|}
\hline Health condition & $\begin{array}{l}\text { Prevalence in } \\
2005\left(\times 10^{3}\right)\end{array}$ & $\begin{array}{l}\text { Prevalence in } \\
2015\left(\times 10^{3}\right)\end{array}$ & $\begin{array}{l}\text { Percentage change } \\
\text { in prevalence, } \\
2005-2015\end{array}$ & $\begin{array}{l}\text { YLDs in } 2005 \\
\left(\times 10^{3}\right)\end{array}$ & $\begin{array}{l}\text { YLDs in } 2015 \\
\quad\left(\times 10^{3}\right)\end{array}$ & $\begin{array}{l}\text { Percentage change in } \\
\text { YLDs, 2005-2015 }\end{array}$ \\
\hline Cancer & $62,673.8$ & $90,497.5$ & 44.4 & 6271.7 & 8569.3 & 36.6 \\
\hline Psoriasis & $67,753.3$ & $79,699.7$ & 17.6 & 5478.8 & 6438.3 & 17.5 \\
\hline Rheumatoid arthritis & $19,779.4$ & $24,491.2$ & 23.8 & 4674.3 & 5777.8 & 23.6 \\
\hline Ischemic stroke & $20,467.3$ & $24,929.0$ & 21.8 & 2999.9 & 3659.9 & 22.0 \\
\hline Gout & $33,387.2$ & $42,214.2$ & 26.4 & 1063.1 & 1342.8 & 26.3 \\
\hline
\end{tabular}

The table compares the rates of prevalence and YLDs between 2005 and 2015 for health states associated with severe levels of disability according to 2015 GBD disability weights. Prevalence refers to the number of people with a health condition; YLDs refers to the number of years lived with disability per health condition. Only health states commonly treated in rehabilitation are presented. 


\section{COPYRIGHT $^{(} 2017$ EDIZIONI MINERVA MEDICA}

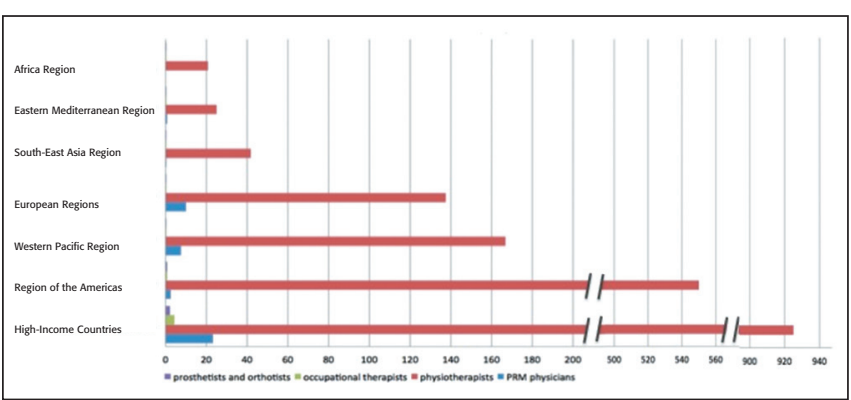

Figure 2.-Density of Rehabilitation Health Professionals per 1 million population by region.

Data for prosthetists and orthotists are from 140 countries; data for occupational therapists are from 79 countries; data for physiotherapists are from 107 countries; data for PRM physicians are from 48 countries. All data from high-income countries (HIC) are reported together. Regional data only contains from LMIC (modified from World Health Organization).$^{9}$

tions associated with severe levels of disability, such as cancer and stroke. The prevalence of these diseases has increased by almost $23 \%$, rising the number of YLDs by more than 17 million over the past decade (Table I). ${ }^{10}$

The main issue is whether the need for rehabilitation can be met worldwide. If we look at the number of rehabilitation health professionals, evidence suggests that the need for rehabilitation is much higher than the services provided, ${ }^{21}$ especially in LMIC. People living in LMIC have poor access to rehabilitation services and in many of these countries the density of rehabilitation trained practitioners is often below 10 per 1 million population and also the number of other health professionals who can deliver rehabilitation is very low worldwide (Figure 2).22, 23 WHO's Global Atlas of the Health Workforce, ${ }^{23}$ which provides information on the general health workforce, does not report comprehensive data on the rehabilitation health professionals; moreover only part of the data are based on official source (regulatory agency or government department), the majority are just an estimate based on knowledge and experience. Moreover, there is no universally agreement on the recommended minimal number of Physical and Rehabilitation Medicine (PRM) physicians, physiotherapists, and speech and language therapists. The World Federation of Occupational Therapists estimated that the minimum number of 750 occupational therapists per 1 million population is required to meet rehabilitation needs. WHO standards for prosthetics and orthotics 24 report that there is a need of at least 5 prosthetists and orthotists per 1 million population.
Another important issue is the underutilization of rehabilitation. Even though high income countries (HIC) have workforce densities several times higher than LMIC, the utilization of rehabilitation services is relatively low. ${ }^{25-29}$ Recognized reasons seems to be lack of accessibility such as transportation barriers, costs of services, long waiting times, and lack of awareness. 25,26

\section{Health information systems and rehabilitation 30}

Health information systems (HIS) are comprehensive, integrated systems designed to manage all the aspects of information relevant to health status and systems. This information can support decision-making in health policy, management and clinical care. ${ }^{31}$

In many LMIC there is a lack of robust and effective HIS and often these countries do not have enough resources to invest in data collection and analysis. ${ }^{32}$ Even in developed countries this data are often out of date or incomplete and therefore there might be a gap between what policy-makers, health professionals and researchers know and what they should know to improve the health of the population. ${ }^{33}$ This scarcity of relevant data is one of the major challenges for monitoring health for the SDG3. ${ }^{34}$

Improving national HIS is fundamental for strengthening the health system. Health status, health system and determinants of health have been recognized by WHO as the three domains of measurement for HIS. WHO has developed a framework and standards for national HIS ${ }^{31}$ and a global reference list of 100 core health indicators to support countries to strengthen their HIS. 35

To strengthen rehabilitation in the health system, health status information should collect, along with mortality and morbidity data, reliable and comprehensive information on functioning and well-being in HIS. ${ }^{36-38 ~ " F u n c t i o n i n g, " ~ a s ~ i n t r o d u c e d ~ i n ~ W H O ' s ~ I n t e r-~}$ national Classification of Functioning, Disability and Health (ICF), refers to the impact of health conditions (injuries, diseases, ageing) on a person's experience in every aspect of his/her life. ${ }^{39}$ Information on functioning is essential to decision-making in rehabilitation at all levels of the health system (user, facility or program, and policy).

Moreover, to understand the rehabilitation needs and the relevant rehabilitation interventions required, infor- 


\section{COPYRIGHT $^{\odot} 2017$ EDIZIONI MINERVA MEDICA}

mation about health determinants (socioeconomic and demographic) as well as health systems are necessary. The last one includes data on inputs (e.g. policy, financing, human resources, and organization and management), outputs (e.g. information and service availability and quality), and outcomes (e.g. service coverage and utilization) of rehabilitation.

\section{Rehabilitation: key for health in the $21^{\text {st }}$ Century ${ }^{40}$}

Rehabilitation, along with prevention, promotion, treatment and support, is a key health strategy to address the full health needs and promote both living longer and living better as stated in SDG3. ${ }^{3}$

Our century is facing the challenges related to the growing demand for rehabilitation. People are living longer and consequently there is an increase in the prevalence of disabling chronic conditions and comorbidities that impact on functioning and well-being. 10, 41, 42 Moreover as the facilitated access to health care has improved more people, including children, survive injury and illness and require rehabilitation for their limitations in functioning. ${ }^{43-45}$

While the need for rehabilitation is increasing, in many parts of the world, health systems do not have the capacity to provide the necessary rehabilitation services. $^{5}$

The WHO Framework on Integrated People-Centered Health Services (IPCHS) put the needs of people and communities, not diseases, at the center of health systems. ${ }^{46}$ Rehabilitation, by its very nature, is a highly person-centered health strategy. It consists of a set of interventions designed to optimize functioning and reduce disability in individuals with a health condition who experience some form of limitation in functioning, across the continuum of care and throughout the lifespan. Therefore, it is critical that quality rehabilitation is included in service delivery models.

Rehabilitation is beneficial not only for the users and their families, but also for the society. It has been reported to effectively reduce hospital length-of-stay, decrease re-admissions, and prevent costly complications. ${ }^{47}$ Moreover rehabilitation improves a person's independence favoring his/her ability to return to work or other social roles and reducing all the costs related to his/her care and support. ${ }^{48}$

In 1978, the Alma Ata Declaration recognized reha- bilitation as a core component of Primary Health Care, nevertheless its representation in primary care is still poor. ${ }^{49}$ To effectively integrate rehabilitation into national health plans and budgets and achieving the goal of universal health coverage, actions required include: strong leadership and governance; adequate funding for rehabilitation; efficient service delivery models; multidisciplinary rehabilitation workforce; affordable assistive products; and integration of rehabilitation data into HIS. 50

The successful development and implementation of rehabilitation is strongly dependent on the political will, which depends on both advocacy and availability of reliable information. Worldwide researchers need to fill the gaps in the evidence for rehabilitation, particularly from a system-level perspective. Priority research questions should investigate on the cost-benefits of rehabilitation; identify facilitators and barriers to rehabilitation; and enable a standardized measure of rehabilitation impact. In addition, it is imperative to strengthen the capacity for rehabilitation research in LMIC through international collaborations.

\section{The Meeting}

\section{Welcome, Key note addresses and personal testimonies}

Etienne Krug, Director of WHO Department for Management of Noncommunicable Diseases, Disability, Violence and Injury Prevention, welcomed the participants and introduced Oleg Chestnov, WHO Assistant Director-General for Noncommunicable Diseases and Mental Health, for the opening remarks. He emphasized the importance of this event as in the $21^{\text {st }}$ century the number of people who experience a loss of function and disability is growing and consequently the number of people in need for rehabilitation. He said that he would ensure that this discussion is brought to a political level connecting it with the SDGs. ${ }^{3}$ After him the Ministers of Health of Botswana, Sri Lanka and Lao People's Democratic Republic took the word ensuring their full support in this call for action. An emotional video explaining the scope of rehabilitation was shown. ${ }^{51}$

As it is usual in meetings involving politicians and not only experts, some patients have been asked to share their own experience with rehabilitation throughout the world. Ritu Sadana, is the coordinator of WHO's work on metrics, monitoring and research on healthy ageing, 


\section{COPYRIGHT $^{(} 2017$ EDIZIONI MINERVA MEDICA}

an editorial advisor for The Bulletin of the World Health Organization, she has over 100 scientific and policy publications. A few years ago, she had a serious accident while she was on a bike ride and went through a successful rehabilitation process lasting more than one year. Gopal Mitra, former Indian Army officer, is Program Specialist, Children with Disabilities in the Disability Section, Program Division at UNICEF. He became blind because of an explosion and presented his experience on how he faced his disability in comparison with what was offered by his country at the time of his accident. Cheat Sokha from Cambodia told the story of how she was shot and became paraplegic when she was 14 years old. She explained that access to rehabilitation in Cambodia is very low, and it was only thanks to her family and to Handicap International and the International Committee of the Red Cross that she received rehabilitation after her accident.

\section{Rehabilitation: key for health in the 21st century}

Alarcos Cieza,52 from the WHO Department for Management of Noncommunicable Diseases, Disability, Violence and Injury Prevention, introduced the role of rehabilitation in the context of the global agenda. She reminded of the SDG3 ${ }^{3}$ and of the second goal of the WHO global disability action plan 2014-2021. ${ }^{7}$ She stressed the importance of the principle of universal health coverage that is at the basis of the provision of high-quality, essential services for Health Promotion, Prevention, Treatment, Rehabilitation and Palliation according to the population needs. Promoting universal health coverage would be critical to protect from financial hardship, including possible impoverishment, due to out-of-pocket expenses. She underlined once again the key role of Rehabilitation, among the other health strategies, to overcome all the needs of individuals with health conditions experiencing disability or limitations in functioning, across the life span and along the continuum of care. She reminded that rehabilitation does not exist in many LMIC and she wished that representatives of these countries would go back with the idea that we are moving together to strengthen rehabilitation as a whole.

Somnath Chatterji, ${ }^{53}$ from the WHO Department for Information, Evidence and Research, started his presentation underlying the key aim of rehabilitation that is to reduce disability and optimize functioning in individuals with health conditions in interaction with their environment and its multidisciplinary and multisectorial nature. He then analyzed the different approaches to estimating needs and the challenges in their measurements.

David McDaid, ${ }^{54}$ from the London School of Economics, presented an analysis of the costs of failing to provide rehabilitation services. He tried to respond to four key economic questions that would be necessary to inform decision makers:

- what are the costs of inaction? That is the economic consequences of not investing in rehabilitation;

- what would be the costs of action? How much rehabilitation would cost;

- what is the cost-effectiveness of action? What would be the ideal balance between the costs of rehabilitation and better population functioning;

- what financial and other incentives might encourage an increased use of cost-effective rehabilitation interventions?

Reviewing the studies on the potential economic impact of rehabilitation is complicated for many reasons: most of the studies are made in HIC; it is not always clear which interventions are considered as rehabilitation; rehabilitation might influence other sectors rather than the health system; and there is a lack of consistency in the methods used to estimate costs. Prof. McDaid concluded his presentation identifying the potential barriers/facilitators to inter-sectoral implementation of rehabilitation, that is the fact that not all rehabilitation is delivered within the health system.

The last contribute in this session was by Anneke Schmider, 55 from the WHO Department for Information, Evidence and Research, who explained the role of HIS. She emphasized that data about rehabilitation is important for policy, financing, service delivery, management and clinical care and that the real challenge is to develop these data systems consistent with broader HIS. In the future, data systems will be: multi-source, data will not be received only from the health sector; multi-method, as they will be collected using differing methodologies; multi-purpose, each record will be useful at a granular level and comparable and consistent for aggregation purposes; and technology-enabled so that larger volumes of data will be captured, and easily linked. 


\section{COPYRIGHT $^{(} 2017$ EDIZIONI MINERVA MEDICA}

\section{Rehabilitation in health systems: implementing WHO recommendations in countries 56}

Recommendations on rehabilitation in health systems are intended for government leaders and health policymakers. They are also relevant for workforce and education and can be useful for professional organizations, academic institutions, civil society and nongovernmental and international organizations.

Strengthening rehabilitation in health systems is crucial to build worldwide high-quality, affordable services, especially in LMIC.5, 6 Inclusion of rehabilitation in universal health coverage will ensure respect for human rights, improve health and provide social and economic benefits. ${ }^{3,50}$ It is well-recognized that rehabilitation has not been a priority for many governments, particularly in LMIC. 5

With the aim to address information gaps and improve rehabilitation service delivery, these recommendations refer to three main statements:

- the WHO report on disability required that Member States "develop, implement, and monitor polices, regulatory mechanisms, and standards for rehabilitation services, as well as promoting access to those services"; 5

- the second objective of the WHO global disability action plan 2014-2021 required "to strengthen and extend rehabilitation, habilitation, assistive technology, assistance and support services, and community-based rehabilitation"; 7

- article n. 26 of the United Nations Convention on the Rights of Persons with Disabilities required States Parties to "organize, strengthen and extend comprehensive habilitation and rehabilitation services and programs." 57

The recommendations were prepared following the standards and procedures for the development of WHO guidelines. ${ }^{58}$ The process involved WHO Secretariat, a Guidelines Development Group (chaired by Prof. Linamara Rizzo Battistella, Past President of the International Society of Physical and Rehabilitation Medicine), research groups (Universities of Toronto, Johns Hopkins Bloomberg School of Public Health and School of Medicine, and University of East Anglia), and an external review group. The WHO Guidelines Review Committee gave the final authorization and endorsement.

Each recommendation was based on a PICO question. Population was always defined as those who need
TABLE II.-List of PICO questions used to conduct evidence reviews for the recommendations. ${ }^{56}$

Questions

A. Should rehabilitation services be integrated into the health system (I) or into the social or welfare system or equivalent (C)?

B. Should rehabilitation services be integrated into primary, secondary and tertiary levels of the health system (I) or integrated only into selected levels of the health system (C)?

C. Should a multi-disciplinary (I) or single-disciplinary (C) rehabilitation workforce be available?

D. Should rehabilitation services be available in both community and hospital settings (I) or only in community or only in hospital settings?

E. Should rehabilitation services for people with complex needs $(\mathrm{P})$ be provided in specialized hospitals and units (I) or only in general wards or non-specialized units (C)?

F. Should financial resources be allocated to rehabilitation (I) or not (C)? G. Should health insurance cover rehabilitation services (I) or not (C)?

Population: those who need rehabilitation; outcomes: better quality of services.

rehabilitation. Outcomes of interest were better quality of services, in terms of accessibility and affordability, with consequent outcomes of increased service use, people-centered care and improved health. Only Intervention and the Comparison varied for each recommendation and were therefore specified in each question. The full list of the PICO questions used to conduct the evidence reviews for the recommendations is listed in Table II.

The recommendations were based on the following principles:

- rehabilitation is fundamental for comprehensive person-centered care; $5,49,59$

- rehabilitation interventions should be applied along the continuum of care; 60,61

- efforts to increase quality, accessibility and affordability of rehabilitation services are necessary to acknowledge the importance of rehabilitation as part of universal health coverage; $49,60,61$

- high-quality rehabilitation services should be accessible and affordable to everyone everywhere. $5,62,63$

The review of evidence undertaken in preparing these recommendations showed that more high-quality research is required on rehabilitation, and especially LMIC should strengthen their information systems and increase their investment in research. Each recommendation was based on the best available evidence and both its strength and assessment of the quality were described.

The strength of a recommendation was decided by 


\section{COPYRIGHT $^{(} 2017$ EDIZIONI MINERVA MEDICA}

the Guideline Development Group, based on factors not related to the quality of the available evidence, but considering factors such as the balance of benefits versus harm and burden of each recommendation. Recommendations were classified as strong, when the desirable effects of adherence to the recommendation exceeded the undesirable ones and therefore the recommendation can be adopted as policy; or conditional, when a debate with the various stakeholders would be necessary before the recommendation can be adopted as policy.

For the evaluation of the quality of the evidence the Guidelines Development Group used the GRADE approach, which is based on the level of certainty of the estimated effects of the intervention. ${ }^{64}$ The ratings are: high, the true effect lies close to the estimated effect; moderate, the true effect is likely to be close to the estimated effect, but there is a possibility that it is substantially different; low, the true effect may be substantially different from the estimated effect; and very low, the true effect is likely to be substantially different from the estimated effect.

Randomized controlled trials, which provide the highest quality of evidence, are not suitable for systems-level interventions. In these cases, case studies or observational and longitudinal studies were considered, as they are more adequate to catch the impact of environmental factors on the implementation of interventions in different contexts. $65-71$

Dissemination and implementation of the recommendations are fundamental steps to reach the goal of improving access to high-quality, affordable rehabilitation services for everyone who needs them. When developing an implementation plan, several barriers may need to be addressed such as the limited knowledge on rehabilitation by policy-makers, limited funding to implement the guidelines, inadequate organizational and administrative support, insufficient skilled workforce, and lack of reliable information. Specific indicators were proposed for monitoring the implementation of the recommendations. The recommendations will be reviewed and updated in five years.

Table III contains a summary of the recommendations with indication of the strength and quality of evidence.

Two good practice statements for assistive products were also published:

- "Financing and procurement policies should be implemented to ensure that assistive products are available to everyone who needs them";
- "Adequate training should be offered to the user, and care provider when appropriate, when assistive products are provided."

Government representatives from Chile, Germany, Pakistan, and the Philippines presented their experience with the integration of rehabilitation in the health system. In particular, German government representatives 72 presented the case of the advantages of rehabilitation in increasing the return to work rate after accidents. Pakistan government representative ${ }^{73}$ presented some statistics on disability and the numbers of rehabilitation workforce, which is mainly constituted by physiotherapists. Rehabilitation Medicine has started only since 1997. One of the future steps would be the creation of rehabilitation positions and the increasing of university affiliations for rehabilitation disciplines. The way forward would be based on the integration of Rehabilitation services in the health systems; Model Disability Survey; ${ }^{74}$ Global Cooperation on Assistive Technology (GATE) initiative; 75 and implementation of both research and evidence-based practice. Finally, the Undersecretary of Health, of the Philippines Department of Health 76 presented the Philippines Health Agenda for 2022 "All for Health Towards Health for All" based on values of equity, efficiency, quality and transparency.

\section{Rehabilitation in health systems: learning from current initiatives}

Three initiatives to implement Rehabilitation in health systems were presented: "Alliance for Health Policy and Systems Research (AHPSR)"; 77 "Program for Improving Mental Health Care (PRIME)"; 78 and "Global Cooperation on Assistive Technology (GATE)." 75

Nhan Tran, ${ }^{79}$ WHO Manager of AHPSR, presented this international collaboration hosted by the WHO, established in 1999, with the mission to promote the generation and use of health policy and systems research as a mean to strengthen the health systems of LMIC. ${ }^{77} \mathrm{He}$ stressed the issue that even when we know what works we have not been successful at ensuring that those interventions are effectively integrated into systems and scaled up.

Dan Chisholm, ${ }^{80}$ from WHO Department for Mental Health and Substance Abuse, presented PRIME. PRIME is an international mental health services research consortium focused on scaling up treatment programs for 


\section{COPYRIGHT $^{\odot} 2017$ EDIZIONI MINERVA MEDICA}

GIMIGLIANO

WHO REHABILITATION 2030

TABLE III.-Recommendations with indication of the strength and quality of evidence. ${ }^{56}$

\begin{tabular}{|c|c|c|c|c|}
\hline & Recommendations & Remarks & $\begin{array}{l}\text { Strength of } \\
\text { recommen- } \\
\text { dation }\end{array}$ & $\begin{array}{l}\text { Quality of } \\
\text { evidence }\end{array}$ \\
\hline A & $\begin{array}{l}\text { Rehabilitation } \\
\text { services should be } \\
\text { integrated into health } \\
\text { systems }\end{array}$ & $\begin{array}{l}\text { 1. Identification of responsibility for rehabilitation governance is necessary for the integration of } \\
\text { rehabilitation services into health systems. } \\
\text { 2. Ministries of health, social welfare, education and labour should work together to promote } \\
\text { efficient person-centred rehabilitation service delivery. } \\
\text { 3. When a shift in governance is required, a phase of transition between ministries is necessary. }\end{array}$ & Conditional & Very low \\
\hline B & $\begin{array}{l}\text { Rehabilitation } \\
\text { services should be } \\
\text { integrated into and } \\
\text { between primary, } \\
\text { secondary and tertiary } \\
\text { levels of health } \\
\text { system }\end{array}$ & $\begin{array}{l}\text { 1. Coordinated and standardized pathways, in and between the different levels of the health system, } \\
\text { are essential to facilitate the continuum of care. } \\
\text { 2. Integration of rehabilitation into and among different levels of the health systems requires skilled } \\
\text { workforce, able to function at primary, secondary and tertiary levels. } \\
\text { 3. For an effective integration of rehabilitation among all levels of the health systems the } \\
\text { collaboration of all health workers is required. } \\
\text { 4. The long-term savings, due to the integration of rehabilitation services in the health systems, can } \\
\text { balance the initial investment required for its implementation. }\end{array}$ & Strong & Very low \\
\hline $\mathrm{C}$ & $\begin{array}{l}\text { A multi-disciplinary } \\
\text { rehabilitation } \\
\text { workforce should be } \\
\text { available }\end{array}$ & $\begin{array}{l}\text { 1. Multi-disciplinary rehabilitation interventions have to be based on the assessment of patient's } \\
\text { needs. } \\
\text { 2. Multi-disciplinary rehabilitation depends on the availability of skilled personnel including } \\
\text { occupational therapists, physiotherapists, PRM physicians, prosthetists and orthotists, } \\
\text { psychologists, social workers and speech and language therapists. } \\
\text { 3. When establishing a multi-disciplinary rehabilitation workforce, it is important to consider the } \\
\text { field of competence of the various health professionals and the needs of the population; when } \\
\text { rehabilitation professionals are insufficient, trans-disciplinary approaches might be used. } \\
\text { 4. Implementing rehabilitation as a multi-disciplinary health service in the health system requires: } \\
\text { a. Ministry for higher education to ensure the education of the various rehabilitation } \\
\text { professionals. } \\
\text { b. Availability of mechanisms for further implement rehabilitation workforce } \\
\text { (professional organization). } 5 \text {, } 65 \\
\text { c. Adequate distribution of rehabilitation workforce, so that multi-disciplinary } \\
\text { rehabilitation services are available everywhere and for all. } \\
\text { d. Funding relevant facilities and programmes to support the provision of } \\
\text { multidisciplinary rehabilitation. } .^{5}\end{array}$ & Strong & High \\
\hline $\mathrm{D}$ & $\begin{array}{l}\text { Both community and } \\
\text { hospital rehabilitation } \\
\text { services should be } \\
\text { available }\end{array}$ & $\begin{array}{l}\text { 1. Adequate distribution of community rehabilitation services. } \\
\text { 2. Support people providing rehabilitation in the community to ensure high-quality services. }\end{array}$ & Strong & Moderate \\
\hline E & $\begin{array}{l}\text { Hospitals should } \\
\text { include specialized } \\
\text { rehabilitation units } \\
\text { for inpatients with } \\
\text { complex needs }\end{array}$ & $\begin{array}{l}\text { 1. Establishment or implementation of specialized rehabilitation units based on: } \\
\text { a. availability of a multi-disciplinary rehabilitation workforce with adequate } \\
\text { specialization to work effectively; } \\
\text { b. allocation of funding for the necessary equipment and consumables for effective } \\
\text { rehabilitation. } \\
\text { 2. Specialized rehabilitation units cannot replace rehabilitation in general wards and in the } \\
\text { community. } \\
\text { 3. Hospitals should attempt to apply a system of needs assessment to ensure the best use of } \\
\text { specialized rehabilitation units. } \\
\text { 4. Implementation of specialized rehabilitation units requires the establishment of internal and } \\
\text { external referral mechanisms. }\end{array}$ & Strong & High \\
\hline $\mathrm{F}$ & $\begin{array}{l}\text { Financial resources } \\
\text { should be allocated } \\
\text { to rehabilitation } \\
\text { services to implement } \\
\text { and sustain the } \\
\text { recommendations on } \\
\text { service delivery }\end{array}$ & $\begin{array}{l}\text { 1. The financial resources invested for implementing the recommendations for rehabilitation } \\
\text { service delivery should be sufficient to ensure equitable access to services for all. } \\
\text { 2. The amount of the financial investment into rehabilitation services should reflect their benefits. } \\
\text { 3. Public, private or not-for profit providers can deliver rehabilitation services. Countries are } \\
\text { encouraged to use the type of service providers that best ensure equitable access to affordable, } \\
\text { high-quality rehabilitation services for everyone who needs them. }{ }^{66} \\
\text { 4. Equitable financing for rehabilitation services can be based on the redistribution of funds to } \\
\text { support people who cannot afford to pay. }{ }^{67} \\
\text { 5. Investments in rehabilitation services should ensure the same quality and access to services for } \\
\text { all people. The indirect costs associated with accessing services, such as transportation, should } \\
\text { be considered. }\end{array}$ & Strong & Very low \\
\hline G & $\begin{array}{l}\text { Where health } \\
\text { insurance exists or is } \\
\text { to become available, } \\
\text { it should cover } \\
\text { rehabilitation services }\end{array}$ & $\begin{array}{l}\text { 1. Health insurance, that is one of the mechanisms used to increase access to health services and } \\
\text { protect people from onerous expenses, }{ }^{68} \text { should always cover rehabilitation expenses. } \\
\text { 2. People living in poverty should not incur out-of-pocket expenses for rehabilitation services. } \\
\text { many settings, particularly LMIC health insurance protects only a minority of the population. }{ }^{30,71} \\
\text { It is important that this mechanism is more largely applied. }\end{array}$ & Conditional & Very low \\
\hline
\end{tabular}

Note: The text of the recommendations is reported as in the original reference. Remarks are a summary of the original reference. 


\section{COPYRIGHT $^{(} 2017$ EDIZIONI MINERVA MEDICA}

priority mental disorders in primary and maternal health care contexts in low resource settings. It is a partnership between academic institutions in five LMIC (South Africa, Ethiopia, Uganda, India, Nepal), and Ministries of Health in each of these countries, and Cross-country partners (academia, NGOs, WHO). PRIME can offer relevant insights for the rehabilitation community in terms of its approach to: district-level service development, program evaluation, and health system strengthening. ${ }^{78}$

Chapal Khasnabis ${ }^{81}$ a WHO Technical Officer presented the Global Cooperation on Assistive Technology. GATE is a flagship program developed by WHO in partnership with UN Agencies, international organizations, donor agencies, professional organizations, academia, and organizations of/for persons with disabilities. GATE initiative has the goal to improve access to high-quality affordable Assistive Health Products, responding to the call to increase access to essential, high-quality, safe, effective and affordable medical products. ${ }^{75}$

\section{Raising awareness of the need for rehabilitation}

Rehabilitation stakeholders (including condition-specific organizations, rehabilitation professional organizations, International and Non-Governmental Organizations (INGOs), rehabilitation professionals working in medical faculties, researchers and professionals working in public health, and editors of scientific journals) were asked to reply to the following three questions:

- What are the three things rehabilitation professional organisations can do in a coordinated effort to raise awareness among policy makers of the need for rehabilitation?

- What are the three things rehabilitation professional organisations can do in a coordinated effort to raise awareness among civil society of the need for rehabilitation?

- What are the three things rehabilitation professional organisations can do in a coordinated effort to raise awareness among the private sector of the need for rehabilitation?

We report on some of the proposed actions as presented by the different groups at the meeting.

In order to raise awareness of the need for rehabilitation among policy makers, the proposed actions included:
- demonstration of the burden of disability; demonstration of the efficacy of rehabilitation as a health intervention; global audit on rehabilitation services; national audits to check the percentage of eligible patients sent to rehabilitation and the quality and outcome of the delivered services; request of commitment of Ministries of Health; implementation of the legal framework to guarantee patients access to rehabilitation when needed; establishment of a Political Rehabilitation (Magna) Charta; and mobilization of Patient Associations; 82

- the importance of generating and/or curating knowledge for evidence-informed policy development; unity of approach, language, and policy among the different professional organizations; and advocacy on how to implement rehabilitation services (countries that successfully developed rehabilitation services in the health system from "minimal" to "national policy" in the last 10 to 15 years might be brought as a successful example); 83

- to collaborate with researchers in order to develop evidence on rehabilitation needs, cost effectiveness and benefits in LMIC; to influence policy makers; to work collaboratively with user groups/disabled people's organizations at international and national levels to develop and integrate habilitation/rehabilitation-related tools and resources into country programming; 84

- to provide well-documented evidence on which informed policy and program decisions can be made. A process of knowledge translation is necessary to convey evidence and data into appropriate messages. ${ }^{85}$

- In order to raise awareness of the need for rehabilitation among civil society, the proposed actions included:

- to demonstrate that the costs of chronic diseases extends beyond the direct costs of medical care and that appropriate rehabilitation would lead to cost savings above all in the working age; 82

- the importance of raising awareness in collaboration with WHO; professional organizations should play a role in the promotion of the rights of persons with disabilities, demonstrating the benefits to society of ensuring universal access to rehabilitation; and empowerment and education that could be done inviting consumers and other stakeholder organizations to participate in congresses and scientific meetings organized by their associations with the goal of educating the general population on the positive impact and availability of rehabilitation interventions; ${ }^{83}$ 


\section{COPYRIGHT ${ }^{\odot} 2017$ EDIZIONI MINERVA MEDICA}

- to plan action oriented research and evaluation of rehabilitation services; to create capacity building to advocate for rehabilitation needs, highlighting the success stories of rehabilitation; and to diffuse the needs/gaps of rehabilitation. Share results of awareness raising efforts with the INGO network, local partners and policy makers. ${ }^{84}$

In order to raise awareness of the need for rehabilitation among private sector, the proposed actions included:

- to focus on equity and access to rehabilitation as a mean to enable and maintain participation and quality of life and to promote the potential role of public-private partnership to enhance rehabilitation service development, delivery, research and innovation; 82

- awareness and education, that is emphasizing that a healthy and buoyant labor market is reliant in part upon a commitment to rehabilitation, both as it relates to optimizing the potential of those with permanent disabilities and those for whom a return to work from illness or injury is desirable and necessary; advocating for a commitment from employers to proactively uphold the rights of employees as they relate to disability and maximize the utilization of assistive technologies; 83
- to influence the private sector to pursue or invest in innovations; to make the business case for the employment sector; and to promote work health and safety. ${ }^{84}$

\section{Rehabilitation in the context of WHO strategies}

Laragh Gollogly, Coordinator of WHO Press and Editor-In-Chief of the WHO Bulletin, chaired this session and underlined the importance of having all these WHO Directors present at the meeting to explain how rehabilitation fits into the scope of their department works.

Ed Kelley, Director of the WHO Department of Service Delivery and Safety (SDS) at the World Health Organization reminded that his Department supports countries in moving their health systems towards universal health coverage through increased access to safe, high quality, effective, people-centered and integrated services. In 2016, the SDS released the Framework on IPCHS which presents a compelling vision of a future in which all people have access to health services that

TABLE IV.-Original and integral text of "Rehabilitation 2030: a call for action." 87

The participants of the meeting Rehabilitation 2030 acknowledge the following:

A. the unmet rehabilitation need around the world, and especially in low-and middle-income countries, is profound;

B. demand for rehabilitation services will continue to increase in light of global health and demographic trends, including population ageing and the increasing number of people living with the consequences of disease and injury;

C. greater access to rehabilitation services is required to "Ensure healthy lives and promote well-being for all at all ages" (Sustainable Development Goal 3 [SDG3]) and to reach SDG Target 3.8 "Achieve universal health coverage, including financial risk protection, access to quality essential health-care services and access to safe, effective, quality and affordable essential medicines and vaccines for all";

D. rehabilitation is an essential part of the continuum of care, along with prevention, promotion, treatment and palliation, and should therefore be considered an essential component of integrated health services;

E. rehabilitation is relevant to the needs of people with many health conditions and those experiencing disability across the lifespan and across all levels of healthcare;

F. rehabilitation is an investment in human capital that contributes to health, economic and social development;

G. the role of rehabilitation is instrumental for effective implementation of the Global strategy and action plan on ageing and health (2016-2020), the Mental health action plan (2013-2020) and the Framework on integrated people-centered health services, and as a contribution to the efforts of the Global Cooperation on Assistive Technology (GATE) initiative;

H. current barriers to strengthen and extend rehabilitation in countries include:

i. $\quad$ under-prioritization by government amongst competing priorities;

ii. absence of rehabilitation policies and planning at the national and sub-national levels;

iii. where both ministries of health and social affairs are involved in rehabilitation there is limited coordination between them;

iv. non-existent or inadequate funding;

v. a dearth of evidence of met and unmet rehabilitation needs;

vi. insufficient numbers and skills of rehabilitation professionals;

vii. absence of rehabilitation facilities and equipment;

viii. the lack of integration into health systems;

I. there is an urgent need for concerted global action by all relevant stakeholders, including WHO Member States and Secretariat, other UN agencies, rehabilitation user groups and service providers, funding bodies, professional organizations, research organizations, and nongovernmental and international organizations to scale up quality rehabilitation. 


\section{COPYRIGHT $^{(} 2017$ EDIZIONI MINERVA MEDICA}

TABLE V.- Original and integral text on the ten areas for action to strengthen rehabilitation. ${ }^{87}$

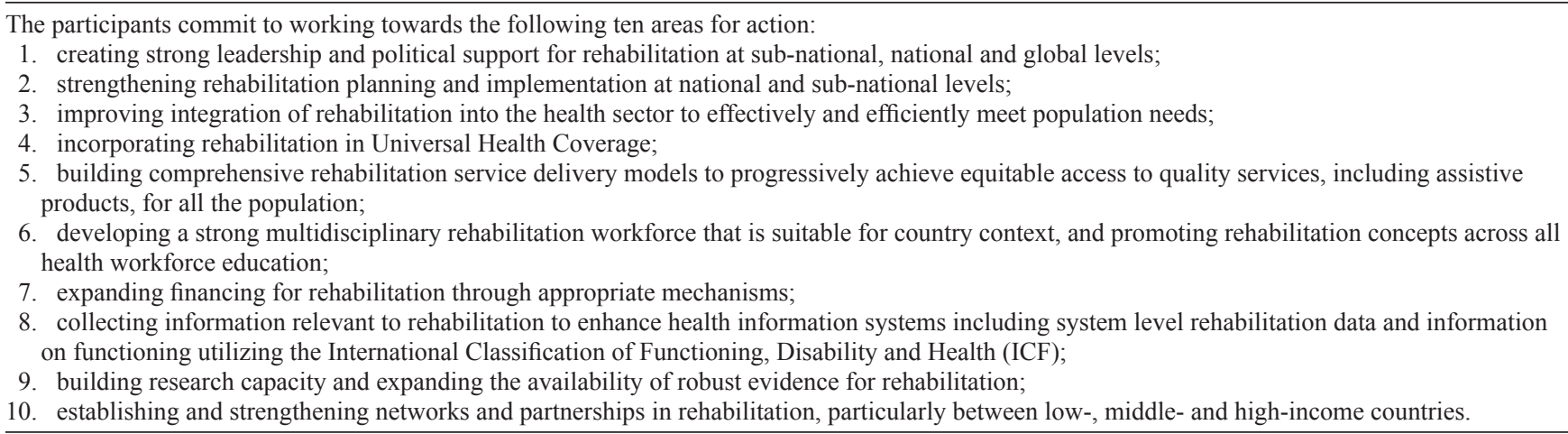

are provided in a coordinated way around their needs, respects their preferences, and are safe, effective, timely, affordable, and of acceptable quality. ${ }^{46}$ Developed as a universal vision, the Framework can be adapted to all countries whether high, medium or low income, with mature or fragile health systems.

Shekhar Saxena, Director of the WHO Department of Mental Health and Substance Abuse stated that rehabilitation apply to all mental health related diseases and therefore is an important part of the Department Agenda.

John Beard, Director of WHO Department of Ageing and Life-course, said that his Department has been working over the past two years to shift the focus of the conceptualization of Healthy Ageing away from the idea that it is just the absence of disease and to focus much more on maintaining individual's functioning. The Agenda of his Department is totally aligned with the Agenda discussed during the meeting. He will make sure to prioritize that integrated care is focused on functioning rather than on disease or prevention and on how to influence the trajectory and capacity across people lives. Rehabilitation services do not need to be delivered in hospitals; they can be delivered in the community and not only by doctors but also by a range of other professionals and community people.

Ties Boerma, Director of the WHO Department of Health Statistics and Informatics within the Innovation, Information, Evidence and Research Cluster, presented his Department, that is engaged with the issue of measurement of health states, mortality monitoring in the context of SDGs ${ }^{6}$ and classifications, including International Classification of Diseases (ICD) and ICF. ${ }^{39} \mathrm{He}$ said that comparable information is still missing and better statistics are needed. As an example, ICF, published 15 years ago, transformed the thinking around disability but its full implementation in terms of coding has still a long way to go.

Etienne Krug, Director of WHO Department for the Management of Noncommunicable Diseases, Disability, Violence and Injury Prevention, thanked all the other Directors for coming at the meeting and sharing their Agendas. For the past 40 years, the Disability and Rehabilitation Team has been focusing too much on disability and not enough on rehabilitation. With this meeting, they want to change this balance a little bit.

\section{Global leadership and call for action}

This session was focused on the political commitment of the various stakeholders to strengthen rehabilitation and included statements from the floor. The full texts of the call for action and of the 10 areas for action to strengthen rehabilitation to which the participants committed are contained in Tables IV and V, respectively. 87 All these areas for action can be grouped, as presented by Alarcos Cieza, into three main areas of work in the WHO Rehabilitation Program to support WHO Member States:

- leadership and governance, e.g., organization of regional meetings to support the implementation of "Rehabilitation 2030: a call for action";

- planning and implementation, e.g., development of a WHO Country Toolkit and dissemination of emergency related documents;

- research and evidence, e.g., Model Disability Survey initiative, conduction of a global survey on rehabilitation, and publication on health policy and system research for LMIC. ${ }^{85-88}$ 


\section{COPYRIGHT $^{\circledR} 2017$ EDIZIONI MINERVA MEDICA}

\section{Conclusions}

This event is very likely to mark the next years in the world of Rehabilitation. In this same issue of the journal we host a paper by Etienne Krug and Alarcos Cieza, who organized the Meeting in Geneva, that is already published as an Editorial in the WHO Bulletin. 89,90 We also present a comment on the Meeting, to start a discussion that we will host in the next numbers of the European Journal of Physical and Rehabilitation Medicine. All our readers are welcomed to present their point of view.

\section{References}

1. World Health Organization. Rehabilitation 2030: a call for action. Concept note. [Internet]. Available from: www.who.int/disabilities/ care/ConceptNote.pdf?ua=1 [cited 2017 March 15].

2. World Health Organization. Rehabilitation 2030: a call for action. Participant List. [Internet]. Available from: www.who.int/disabilities/ care/PartcipantListREHAB2030.pdf?ua=1 [cited 2017 March 15].

3. United Nations. Sustainable Development Knowledge Platform. Sustainable Development Goals. 2015 [Internet]. Available from: https:// sustainabledevelopment.un.org/sdgs [cited 2017 March 15].

4. World Health Organization. Rehabilitation 2030: a call for action. [Internet]. Available from: www.who.int/disabilities/care/rehab-2030/ en/ [cited 2017 March 15].

5. World Health Organization and The World Bank, World report on disability. Geneva, Switzerland: Geneva: WHO Press; 2011.

6. World Health Organization, World Health Statistics 2016. Monitoring Health for the SDGs. Geneva, Switzerland: Geneva: WHO Press; 2016.

7. World Health Organization. WHO global disability action plan 2014 2021. Better health for all people with a disability. Geneva: WHO Press; 2015.

8. Department for International Development, Disability, poverty and development. 2000: London, United Kingdom. [Internet]. Available from: www.gov.uk/government/organisations/department-for-international-development/about [cited 2017 March 15].

9. World Health Organization. Rehabilitation 2030: a call for action. The need to scale up rehabilitation. [Internet]. Available from: www.who.int/disabilities/care/NeedToScaleUpRehab. pdf?ua=1 [cited 2017 March 15].

10. GBD 2015 Disease and Injury Incidence and Prevalence Collaborators. Global, regional, and national incidence, prevalence, and years lived with disability for 310 diseases and injuries, 1990-2015: a systematic analysis for the Global Burden of Disease Study 2015. Lancet 2016;388:1545-602.

11. Scott DA, Mills M, Black A, Cantwell M, Campbell A, Cardwell CR, et al. Multidimensional rehabilitation programmes for adult cancer survivors. Cochrane Database Syst Rev 2013;(3):CD007730.

12. Dalal HM, Doherty P, Taylor RS. 2015. Cardiac rehabilitation. BMJ 2015;351:h5000

13. Lacasse Y, Goldstein R, Lasserson TJ, Martin S. Pulmonary rehabilitation for chronic obstructive pulmonary disease. Cochrane Database Syst Rev 2006;(4):CD003793.

14. Pollock A, Baer G, Campbell P, Choo PL, Forster A, Morris J, et al. Physical rehabilitation approaches for the recovery of function and mobility after stroke. Major update. Stroke 2014;45:e202.

15. Khan F, Ng L, Turner-Stokes L. Effectiveness of vocational rehabilitation intervention on the return to work and employment of persons with multiple sclerosis. Cochrane Database Syst Rev 2009;(1):CD007256.
16. Crowther R, Marshall M, Bond GR, Huxley P. Vocational rehabilitation for people with severe mental illness. Cochrane Database Syst Rev 2001;(2):CD003080.

17. Kim H, Colantonio A. Effectiveness of rehabilitation in enhancing community integration after acute traumatic brain injury: a systematic review. Am J Occup Ther 2010;64:709-19.

18. Williams RM, Westmorland MG, Lin CA, Schmuck G, Creen M. Effectiveness of workplace rehabilitation interventions in the treatment of work-related low back pain: a systematic review. Disabil Rehabil 2007;29:607-24.

19. O'Brien KK, Ibáñez-Carrasco F, Solomon P, Harding R, Cattaneo J, Chegwidden W, et al. Advancing research and practice in HIV and rehabilitation: a framework of research priorities in HIV, disability and rehabilitation. BMC Infect Dis 2014;14:1.

20. Bangirana P, Allebeck P, Boivin MJ, John CC, Page C, Ehnvall A, et al. Cognition, behaviour and academic skills after cognitive rehabilitation in Ugandan children surviving severe malaria: a randomised trial. BMC Neurol 2011;11:1.

21. Gupta N, Castillo-Labord C, Landry MD. Health-related rehabilitation services: assessing the global supply of and need for human resources. BMC Health Serv Res 2011;11:1.

22. World Health Organization. The world health report 2006: working together for health. Geneva: WHO Press; 2006.

23. World Health Organization. Global atlas of the health workforce. [Internet]. Available from: http://apps.who.int/gho/data/node.main. A1444?lang=en\&showonly=HWF [cited 2017 March 15].

24. World Health Organization. Standards for prosthetics and orthotics. Geneva: WHO Press; 2016 (in press).

25. Eldar R, Kullmann L, Marincek C, Sekelj-Kauzlarić K, Svestkova $\mathrm{O}$, Palat M. Rehabilitation medicine in countries of central/eastern Europe. Disabil Rehabil 2008;30:134-41.

26. Bjarnason-Wehrens B, McGee H, Zwisler AD, Piepoli MF, Benzer W, Schmid JP, et al. Cardiac rehabilitation in Europe: results from the European Cardiac Rehabilitation Inventory Survey. Eur J Cardiovasc Prev Rehabil 2010;17:410-8.

27. McNaughton H, McRae A, Green G, Abernethy G, Gommans J. Stroke rehabilitation services in New Zealand: a survey of service configuration, capacity and guideline adherence. $\mathrm{N} Z \mathrm{Z}$ Med $\mathrm{J}$ 2014; $127: 10-9$

28. Grace SL, Turk-Adawi K, Santiago de Araujo Pio C, Alter DA. Ensuring cardiac rehabilitation access for the majority of those in need: a call to action for Canada. Canadian J Cardiol 2016;32:S358-64.

29. Chang WH, Shin YI, Lee SG, Oh GJ, Lim YS, Kim YH. Characteristics of inpatient care and rehabilitation for acute first-ever stroke patients. Yonsei Med J 2015;56:262-70.

30. World Health Organization. Rehabilitation 2030: a call for action Health information systems and rehabilitation. [Internet]. Available from: www.who.int/disabilities/care/HISandRehabilitation.pdf?ua=1 [cited 2017 March 15].

31. World Health Organization. Framework and standards for country health information systems. Second edition. Geneva: WHO Press; 2012.

32. Upadhaya N, Jordans MJ, Abdulmalik J, Ahuja S, Alem A, Hanlon $\mathrm{C}$, et al. Information systems for mental health in six low and middle income countries: cross country situation analysis. Intern J Mental Health Sys 2016;10:60.

33. Heeks R. Health information systems: Failure, success and improvisation. Intern J Med Informatics 2006;75:125-37.

34. World Health Organization. World Health Statistics 2016. Monitoring health for the SDGs. Geneva: WHO Press; 2016.

35. World Health Organization. 2015 Global reference list of 100 core health indicators. Geneva: WHO Press; 2015.

36. Bradley SM, Rumsfeld JS, Ho PM. Incorporating health status in routine care to improve health care value: the VA patient reported health status assessment (PROST) system. JAMA 2016;316:487-8.

37. World Health Organization. The global strategy and action plan on ageing and health 2016-2020. [Internet]. Available from: http://who. int/ageing/GSAP-Summary-EN.pdf?ua=1 [cited 2017 March 15].

38. Stucki G, Bickenbach J, Melvin J. Strengthening rehabilitation in health systems worldwide by integrating information on functioning 
in national health information systems. Am J Phy Med Rehabil 2016 Dec 15. [Epub ahead of print]

39. World Health Organization. International classification of functioning, disability and health: ICF. Geneva: World Health Organization; 2001.

40. World Health Organization. Rehabilitation 2030: a call for action Rehabilitation: key for health in the $21^{\text {st }}$ century [Internet]. Available from: www.who.int/disabilities/care/KeyForHealth21stCentury. pdf?ua=1 [cited 2017 March 15]

41. Chatterji S, Byles J, Cutler D, Seeman T, Verdes E. Health, functioning, and disability in older adults-present status and future trends. Lancet 2015;385:563-75.

42. Stucki G, Bickenbach J, Gutenbrunner C, Melvin J. Rehabilitation: the health strategy of the $21^{\text {st }}$ century. J Rehab Med 2017 Jan 31. [Epub ahead of print]

43. Fleury AM, Salih SA, Peel NM. Rehabilitation of the older vascular amputee: a review of the literature. Geriatr Gerontol Int 2013;13:264-73.

44. Proctor F. Rehabilitation of the burn patient. Indian J. Plast Surg 2010;43(Suppl):S101-13

45. Nas K, Yazmalar L, Sah V, Aydin A, Ones K. Rehabilitation of spinal cord injuries. World J Orthop 2015;6:8-16.

46. World Health Organization. WHO Framework on Integrated Peoplecentred Health Services (IPCHS) [Internet]. Available from: www. who.int/servicedeliverysafety/areas/people-centred-care/en/ [cited 2017 March 15].

47. Stucki G, Stier-Jarmer M, Grill E, Melvin J. Rationale and principles of early rehabilitation care after an acute injury or illness. Disabil Rehabil 2009;27:353-9.

48. Turner-Stokes L, Williams H, Bill A, Bassett P, Sephton K. Cost-efficiency of specialist inpatient rehabilitation for working-aged adults with complex neurological disabilities: a multicentre cohort analysis of a national clinical dataset. BMJ Open 2016;6(2).

49. World Health Organization. Declaration of Alma-Ata. International Conference on Primary Health Care, Alma-Ata, USSR, 6-12 September 1978 [Internet]. Available from: www.who.int/publications/ almaata_declaration_en.pdf?ua=1 [cited 2017 March 15].

50. World $\bar{H}$ ealth Organization. Universal Health Coverage [Internet]. Available from: http://www.who.int/mediacentre/factsheets/fs395/ en/ [cited 2017 March 15].

51. World Health Organization. Rehabilitation 2030: a call for action. Video: "Rehabilitation: key for health in the 21 st century" [Internet]. Available from: www.youtube.com/watch? $\mathrm{v}=\mathrm{a} 8 \mathrm{uaRziX}$ ruc\& feature $=$ youtu.be [cited 2017 March 15].

52. World Health Organization. Rehabilitation 2030: a call for action Cieza A. Rehabilitation in the context of the global agenda [Internet] Available from: http://www.who.int/disabilities/care/1000-Rehabilitation-key-for-health-in-the-21-century-Alarcos-Cieza.pdf?ua=1 [cited 2017 March 15].

53. World Health Organization. Rehabilitation 2030: a call for action. Chatterji S. The need to scale up rehabilitation [Internet]. Available from: www.who.int/disabilities/care/1000-The-need-to-scale-uprehabilitation-Somnath-Chatterji.pdf?ua=1 [cited 2017 March 15].

54. World Health Organization. Rehabilitation 2030: a call for action. McDaid D. The costs of failing to provide rehabilitation services [Internet]. Available from: http://www.who.int/disabilities/care/1000The-costs-of-failing-to-provide-rehab-David-McDaid.pdf?ua=1 [cited 2017 March 15].

55. World Health Organization. Rehabilitation 2030: a call for action Schmider A. Improving data for rehabilitation in health information systems [Internet]. Available from: http://www.who.int/disabilities/ care/1000-Improving-data-for-rehab-in-HIS-Anneke-Schmider. pdf?ua $=1$ [cited 2017 March 15].

56. Rehabilitation in health systems. Geneva: World Health Organization; 2017. Licence: CC BY-NC-SA 3.0 IGO.

57. United Nations. Convention on the Rights of Persons with Disabilities. Art. 26 [Internet]. Available from: www.un.org/development/desa/ disabilities/convention-on-the-rights-of-persons-with-disabilities/ article-26-habilitation-and-rehabilitation.html [cited 2017 March 15].

58. World Health Organization. WHO handbook for guideline development, Second edition. Geneva: WHO Press; 2014.
59. Frank AO, Chamberlain MA. Rehabilitation: an integral part of clinical practice. Occup Med 2006;56:289-93.

60. Stucki G, Cieza A, Melvin J. The International Classification of Functioning, Disability and Health: a unifying model for the conceptual description of the rehabilitation strategy. J Rehabil Med 2007;39:279-85.

61. Meyer T, Gutenbrunner C, Bickenbach J, Cieza A, Melvin J, Stucki G. Towards a conceptual description of rehabilitation as a health strategy. J Rehabil Med 2011;43:765-9.

62. World Health Organization. WHO global strategy on people-centred and integrated health services. Interim report. Geneva: WHO Press; 2015.

63. World Health Organization. People-centred and integrated health services: an overview of the evidence: interim report. Geneva: WHO Press; 2015

64. GRADE Networking Group [Internet]. Available from: www.gradeworkinggroup.org [cited 2017 March 15].

65. World Health Organization. Increasing access to health workers in remote and rural areas through improved retention: global policy recommendations. Geneva: WHO Press; 2010.

66. Mossialos E, Dixon A. Funding health care: an introduction. In: Mossialos E, Dixon A, Figueras J, editors. Funding health care: options for Europe. Buckingham: Open University Press; 2002. p. 1-30.

67. Green A, Ali B, Ross D. Resource allocation and budgetary mechanisms for decentralized health systems: experiences from Balchistan, Pakistan. Bull World Health Organ 2000;78:1024-35.

68. Jeffrey AE, Newacheck PW. Role of insurance for children with special health care needs: a synthesis of the evidence. Pediatrics 2006;118:e1027-38

69. United Nations. Convention on the Rights of Persons with Disabilities. Art. 26 [Internet]. Available from: www.un.org/development/ desa/disabilities/convention-on-the-rights-of-persons-with-disabilities/article-28-adequate-standard-of-living-and-social-protection. html [cited 2017 March 15].

70. Turner-Stokes L, Paul S, Williams H. Efficiency of specialist rehabilitation in reducing dependency and costs of continuing care for adults with complex acquired brain injuries. J Neurol Neurosurg Psychiatry 2006;77:634-9.

71. Howard-Wilsher S, Irvine L, Fan H, Shakespeare T, Suhrck M, Horton $\mathrm{S}$, et al. Systematic overview of economic evaluations of healthrelated rehabilitation. Disabil Health J 2016;9:11-25.

72. World Health Organization. Rehabilitation 2030: a call for action. Rossbach G, Breuer J. Government representatives Germany [Internet]. Available from: www.who.int/disabilities/care/1130-Germany. pdf?ua =1 [cited 2017 March 15].

73. World Health Organization. Rehabilitation 2030: a call for action. Punchi D. Government representative Pakistan [Internet]. Available from: www.who.int/disabilities/care/1130-Pakistan.pdf?ua=1 [cited 2017 March 15]

74. World Health Organization. Model Disability Survey [Internet]. Available from: www.who.int/disabilities/data/model-disability-survey.pdf?ua=1 [cited 2017 March 15].

75. World Health Organization. Global Cooperation on Assistive Technology (GATE). [Internet]. Available from: http://www.who.int/disabilities/technology/gate/en/ [cited 2017 March 15].

76. World Health Organization. Rehabilitation 2030: a call for action. Valle H. Government representative Philippines [Internet]. Available from: www.who.int/disabilities/care/1130-Philippines.pdf?ua=1 [cited 2017 March 15].

77. World Health Organization. Alliance for Health Policy and Systems Research (AHPSR) [Internet]. Available from: www.who.int/alliance-hpsr/en/ [cited 2017 March 15].

78. World Health Organization. Programme for Improving Mental Health Care (PRIME) [Internet]. Available from: www.prime.uct.ac.za [cited 2017 March 15]

79. World Health Organization. Rehabilitation 2030: a call for action Tran N. Alliance for Health Policy and Systems Research [Internet]. Available from: www.who.int/alliance-hpsr/about/en/ [cited 2017 March 15]

80. World Health Organization. Rehabilitation 2030: a call for action Chisholm D. Programme for Improving Mental Health Care (PRIME) 


\section{COPYRIGHT $^{(} 2017$ EDIZIONI MINERVA MEDICA}

GIMIGLIANO

WHO REHABILITATION 2030

[Internet]. Available from: www.who.int/disabilities/care/1400Improving-mental-health-care-Dan-Chisholm.pdf?ua=1 [cited 2017 March 15].

81. World Health Organization. Rehabilitation 2030: a call for action Khasnabis C. Global Cooperation on Assistive Technology (GATE) [Internet]. Available from: www.who.int/disabilities/technology/gate/ en/ [cited 2017 March 15].

82. World Health Organization. Rehabilitation 2030: a call for action Raising Awareness of the Need for Rehabilitation. Condition-specific Organizations [Internet]. Available from: http://www.who.int/disabilities/care/1600-Raising-awarness-Condition-specific-organizations. pdf?ua $=1$ [cited 2017 March 15]

83. World Health Organization. Rehabilitation 2030: a call for action. Raising Awareness of the Need for Rehabilitation. Rehabilitation Professional Organizations. [Internet]. Available from: http://www. who.int/disabilities/care/1600-Raising-awarness rehab-professionalbodies.pdf?ua=1 [cited 2017 March 15].

84. World Health Organization. Rehabilitation 2030: a call for action. Raising Awareness of the Need for Rehabilitation. International and Nongovernmental Organizations [Internet]. Available from: www. who.int/disabilities/care/RaisingAwarenessIGOsNGOsTalkingPoints.pdf?ua=1 [cited 2017 March 15].
85. World Health Organization. Rehabilitation 2030: a call for action. Raising Awareness of the Need for Rehabilitation. Researchers and Professionals working in Public Health [Internet]. Available from: www.who.int/disabilities/care/1600-Raising-awareness-publichealth.pdf?ua=1 [cited 2017 March 15].

86. World Health Organization. Family of International Classifications. International Classification of Diseases [Internet]. Available from: www.who.int/classifications/icd/en/ [cited 2017 March 15].

87. World Health Organization. Rehabilitation 2030: a call for action. The call for action [Internet]. Available from: http://www. who.int/disabilities/care/CallForAction.pdf?ua=1 [cited 2017 March 15].

88. World Health Organization. Rehabilitation 2030: a call for action. Cieza A. The call for action [Internet]. Available from: http:// www.who.int/disabilities/care/1045-Call-for-Action-Alarcos-Cieza. pdf?ua $=1$ [cited 2017 March 15].

89. Krug E, Cieza A. Strengthening health systems to provide rehabilitation services Bull World Health Organ 2017;95:167.

90. World Health Organization. Rehabilitation 2030: a call for action. Meeting Report. [Internet]. Available from: http://www.who.int/ disabilities/care/Rehab2030MeetingReport2.pdf?ua=1 [cited 2017 March 15].

Conflicts of interest.-The authors certify that there is no conflict of interest with any financial organization regarding the material discussed in the manuscript. Article first published online: March 23, 2017. 